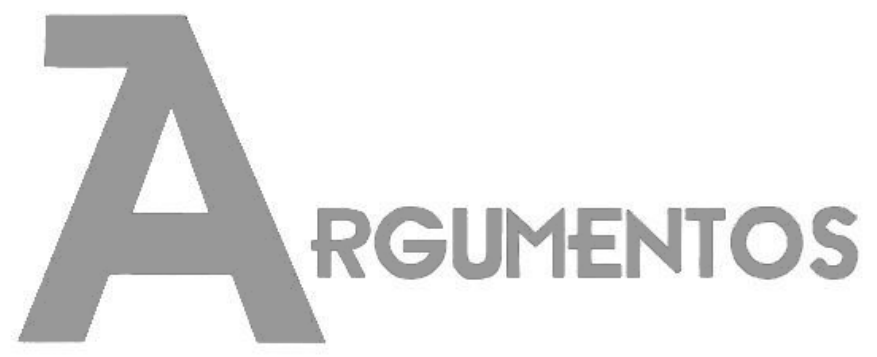

Vol. 16, n. 1, jan./jun. 2019 ISSN: 2527-2551 (online)

http://www.periodicos.unimontes.br/argumentos

\title{
Incerteza e suspensão: notas sobre a vida material e política da infraestrutura no cotidiano da favela Santa Marta/RJ
}

\author{
Apoena Mano ${ }^{1}$ \\ Recebido em: 15/12/2018 \\ Aprovado em: 30/04/2019
}

Resumo: Neste artigo, a partir de uma análise crítica sobre a produção e manutenção de infraestruturas urbanas, pretende-se revelare anal isar as "relações frágeis" entre as pessoas, as coisas e as instituições públicas e privadas que procuram governá-las. Os relatosse desenvolvem a partir de três situações na favela Santa Marta/RJ: os agenciamentos em torno das obras interrompidas de um conjunto habitacional; as incertezas e efeitos relacionados à regularização de serviços de eletricidade na favela; e o contraste sobre promessas e suspensões relacionadas ao contexto presente. $O$ recorte temporal é o momento posterior ao encerramento dos Jogos Olímpicos 2016. Conclui-se que, apesar da criação de uma narrativa de promessas e expectativas, a sensação que permeia o cotidiano dos moradores da favela se caracteriza pela suspensão e incertezas.

Palavras-chave: Favela; Infraestrutura; UPP; Violência Urbana; Rio de Janeiro.

\section{Incertidumbre y suspension: notas sobre la vida material y política de la infraestructura en el cotidiano de la favela Santa Marta / RJ}

Resumen: En este artículo, a partir de un análisis crítico sobre la producción y mantenimiento de infraestructuras urbanas, se pretende revelar y analizar las "relaciones frágiles" entre las personas, las cosas y las instituciones públicas y privadas que buscan gob ernarlas. Los relatos se desarrollan a partir de tres situaciones en la favela Santa Marta / RJ: los agenciamientos en tomo a las obras interrumpidas de un conjunto habitacional; las incertidumbres y efectos relacionados con la regularización de servicios de electricidad en la favela; y el contraste sobre promesas y suspensiones relacionadas con el contexto presente. El recorte temporal es el momento posterior al cierre de los Juegos Olímpicos 2016. Se concluye que, a pesar de la creación de una narrativa de promesas y expectativas, la sensación que impregna el cotidiano de los habitantes de la favela se caracteriza por la suspensión e incertidumbres.

Palabras-clave: Favela; Infraestructura; UPP; Violencia urbana; Rio de Janeiro.

\footnotetext{
1 Mestre em Ciências Sociais pela Universidade Estadual do Rio de Janeiro - Rio de Janeiro, Brasil. E-mail:< apoenasd@gmail.com>.ORCID: https://orcid.org/0000-0001-9114-0209
} 
Dossiê | Incerteza e suspensão: notas sobre a vida material e política da infraestrutura no cotidiano da favela Santa Marta/RJ (MANO, Apoena)

\title{
Uncertainity and suspension: notes on the material and political life of the infrastructure in the daily life of the favela Santa Marta / RJ
}

\begin{abstract}
In this article, based on a critical analysis of the production and maintenance of urban infrastructures, is intended to reveal and analyze the "fragile relationships" between people, things and public and private institutions that seek to govern them. The reports are developed from three situations in the favela Santa Marta / RJ: the assemblies around the interrupted works of a housing complex; the uncertainties and effects related to the regularization of electricity services in the favela; and the contrast over promises and suspensions related to the present context. The temporal cut is the moment after the closure of the 2016 Olympic Games. It is concluded that, despite the creation of a narrative of promises and expectations, the feeling that permeates the daily life of the residents of the favela is characterized by suspension and uncertainties.
\end{abstract}

Keywords: Favela, Infrastructure, UPP; Urban Violence; Rio de Janeiro.

\section{Introdução ${ }^{2}$}

\begin{abstract}
"A descontinuidade da política de pacificação na favela Santa Marta, em Botafogo, coincide com a incompletude das obras de reurbanização, simbolizada pelo esqueleto de um conjunto habitacional bem à esquerda da encosta de quem a vê do asfalto“. (JORNAL DO BRASIL, 2018)
\end{abstract}

A cidade do Rio de Janeiro foi atingida por diversas intervenções urbanas sob a justificativa de "preparação do país" para a Copa do Mundo FIFA 2014 e Jogos Olímpicos 2016, entre outros. Após diversas tentativas frustradas, enfim são conquistadas justificativas que legitimam uma agenda de "revitalização urbana" na cidade, envolvendo projetos que produzem expectativas relacionadas à alteração da qualidade de vida de populações como argumento para sua execução ${ }^{3}$. O trecho da reportagem acima, publicada em Abril de 2018, ilustra o cenário da favela Santa Marta dois anos após o encerramento das Olimpíadas.

O projeto das Unidades de Polícia Pacificadora - UPPs é notado como um acontecimento emblemático daquele momento - sendo referido por distintos agentes como "a resolução do problema da favela" (BURGOS, 1998; BURGOS et al., 2011). Em

\footnotetext{
2 Este artigo é resultado de discussões realizadas no curso "Precariedades, cotidiano e micropolíticas: habitando a cidade", oferecido no semestre 2018.1 do Programa de Pós-Graduação em Ciências Sociais da Uerj. Agradeço aos outros participantes da turma e, principalmente, a Patricia Birman, Marcia Leite, Liliana Sanjurjo e Camila Pierobon.

${ }^{3}$ Como argumenta Gutterres (2016), o acionamento discursivo do termo "revitalização" chama a atenção durante este momento tanto pela fabricação de normas e lineamentos que definem como o espaço será narrado e quem vive ou viverá nele, mas ta mbém evidencia o questionamento sobre qual vida es tá sendo ressaltada.
} 
Dossiê | Incerteza e suspensão: notas sobre a vida material e política da infraestrutura no cotidiano da favela Santa Marta/RJ (MANO, Apoena)

sua inauguração, esta política vinculada à Secretaria de Segurança Pública recebeu visibilidade porque, além de "combater a violência nas favelas", também teria atributos relacionados à "entrada na favela" de serviços públicos, infraestrutura, investimentos privados, organizações sociais e oportunidades de comércio ${ }^{4}$. Atributos sobre uma suposta "integração das favelas à parte formal da cidade" que permaneceram como promessas. Também em 2018, o jornal El País divulga uma reportagem intitulada "UPPS, mais uma história de esperança e fracasso na segurança pública do Rio". Entre críticas e descrições contundentes sobre o aparente desmonte da política de segurança pública, o texto informa que "o modelo que representou nos últimos anos a esperança de um Rio mais seguro se mostra esgotado, após colecionar uma série de fracassos e escândalos nos últimos anos" (EL PAIS, 2018).

No momento posterior aos Jogos Olímpicos de 2016, foi possível perceber em diversas formas discursivas, como no caso da reportagem destacada, a substituição continuada e recorrente de termos relacionados a promessas, como "oportunidade", "melhoria" e "renovação", por relatos de suspensão, como "descontinuidade", "interrupção" e "incerteza". O contexto da favela Santa Marta, produzida como "favela modelo" - um laboratório do projeto de "pacificação" - pode ser tomado como parâmetro para a análise da descontinuidade e do esgotamento de políticas urbanas neste período. Por exemplo, a mencionada referência ao conjunto habitacional que estava sendo construído, onde 64 apartamentos seriam oferecidos aos moradores da favela. Além da espontânea interrupção das obras, as condições atuais do local são descritas na reportagem como "apenas ruínas" (JORNAL DO BRASIL, 2018).

Os antropólogos Anand, Gupta e Appel (2018) enfatizam que práticas e discursos do Estado sobre territórios e populações podem ser analisados a partir de contextos de planejamento, produção e execução da renovação infraestrutural urbana. No contexto da "pacificação", projetos emblemáticos foram produzidos como forma de inscrever as favelas na paisagem urbana, produzindo uma sensação de "inclusão" perante a cidade

\footnotetext{
4 Esta "gramática da pacificação" se desenvolve subordinada a um controle militarizado do território, permitindo que o Estado exercesse sua soberania implementando sua presença efetiva por meio de suas instituições específicas e concessões de serviços públicos que realizariam a referida integração urbana (LEITE, 2017).
} 
Dossiê | Incerteza e suspensão: notas sobre a vida material e política da infraestrutura no cotidiano da favela Santa Marta/RJ (MANO, Apoena)

dita "formal" (CAVALCANTI, 2013) ${ }^{5}$. Analisar criticamente estes projetos fornece evidências sobre as formas de governo no momento posterior aos Jogos Olímpicos. Por exemplo, uma reportagem do jornal Extra informa sobre uma situação que pode ser considerada uma significativa materialização da continuidade do projeto das UPPs considerando seus atributos de esgotamento, interrupção e fracasso: fechados desde o final de 2016, os "teleféricos do Alemão e da Providência viram sucata" (EXTRA, 2018). Desta forma, uma análise da vida material e política constitutiva das infraestruturas pode revelar "relações frágeis" entre as pessoas, as coisas e as instituições que procuram governá-las (ANAND; GUPTA; APPEL, 2018). Essas relações frágeis tornam a infraestrutura um local produtivo para examinar a constituição, a manutenção e a reprodução da vida política, econômica e social de determinados territórios.

Em resposta à reportagem sobre as obras do conjunto habitacional na favela Santa Marta, a Assessoria de Imprensa do Governo Estadual do Rio de Janeiro informou que o custo do projeto foi de $\mathrm{R} \$ 10,1$ milhões. Sua realização teve início em novembro de 2011 e foi interrompida no ano seguinte, onde pouco mais da metade do projeto foi executado pela Empresa de Obras Públicas do Estado do Rio - Emop. Sobre a suspensão das obras, a Assessoria revelou que "não se sabe quando o trabalho será retomado". Tendo como referência esta conjuntura, onde um órgão oficial do Estado revela descaso e omissão ao ser questionado sobre a continuidade do projeto, torna-se necessário apreender que a conclusão pode não ser o único resultado possível em projetos de infraestrutura. A suspensão, ao invés de ser uma fase temporária de um projeto, precisa ser teorizada como sua própria condição de ser. É exatamente esta relação de indefinição que permite pensar sobre uma política particular do presente (APPEL; ANAND; GUPTA, 2015).

Em outra reportagem, publicada pelo jornal O Globo em 2012, momento central da construção discursiva da "revitalização" da cidade e auge da reverberação da "favela modelo", são denunciados diversos problemas de infraestrutura e urbanização que afetam o cotidiano da favela Santa Marta, como má-distribuição de água, falta de

\footnotetext{
${ }^{5}$ Em descrição sobre o momento de inauguração da UPP na Favela da Providência, Birman, Fernandes e Pierobon (2017) afirmam que a favela tornou-se cenário privilegiado de "mais um espetáculo midiático da pacificação". Foram afirmados de maneira repetida os grandes benefícios previstos para a favela com a expulsão do tráfico e a realização de obras para finalidades turísticas e urbanísticas.
} 
Dossiê | Incerteza e suspensão: notas sobre a vida material e política da infraestrutura no cotidiano da favela Santa Marta/RJ (MANO, Apoena)

eletricidade, esgoto a céu aberto, entre outros. Em entrevista sobre suas expectativas naquele momento, um morador afirma que "disseram que agora o Estado se faria presente aqui". Entretanto, ele complementa afirmando que desde 2008 a única obra relevante teria sido o início da "construção do prédio" - o conjunto habitacional mencionado anteriormente. Procurados pela produção da reportagem, os órgãos responsáveis se esquivaram: a Secretaria Municipal de Obras informou que "não faz intervenções na favela" e a responsabilidade pela rede de águas pluviais no Santa Marta seria do Governo do Estado ou da Secretaria Municipal de Habitação. A SMH, por sua vez, afirmou que não atua na favela ${ }^{6}$. Apesar das denúncias veiculadas pela reportagem, o Governo do Estado manifestou, através de uma nota oficial, que "fez obras de infraestrutura no local", investindo o valor de $R \$ 27,7$ milhões na ocasiã o (O GLOBO, 2012). Aqui, em complemento à discussão anterior, percebe-se um eixo analítico onde se vinculam o governo de populações e a vida política da infraestrutura. Ainda que finalizados, as formas como os projetos são concretizados podem ser interpretadas principalmente pela precarização, além de ameaças por falhas, quebras e fracassos produzindo a sensação de ausência por parte das populações.

Devido a formas de administração específicas por parte do Estado, as favelas nunca foram efetivamente integradas ao resto da cidade (BURGOS, 1998; LEITE, 2017) ${ }^{7}$. Ao invés de examinar as favelas a partir da "ausência do Estado", recorro ao entendimento do "Estado que se faz ausente" na vida destas pessoas, sob atuação em configurações específicas. Em diálogo com o trabalho das antropólogas Veena Das e Deborah Poole (2004), a favela Santa Marta é aqui compreendida como um "lugar de reconfiguração do Estado" - principalmente por ter sido mencionada freqüentemente pela mídia, a sociedade civil e o próprio Estado a partir de termos como "favela

\footnotetext{
${ }^{6}$ Apesar de "não atuar em favelas", durante este período a Secretaria Municipal de Habitação tornou-se reconhecida por sua relação com políticas de remoções de moradias. Isso ocorreu pela prática de divulgar as remoções que seriam parte de processos de urbanização através de marcações com a sigla "SMH" na parede de casas, acompanhada por um número. Como demonstra Gutterres (2016), o número pichado era "materialmente visível e, por isso, gerador de um sentimento de culpa, de sujeira, de ilegalidade, de acusação, que era extremamente violento para quem passava por essa experiência".

7 Não estou considerando "favelas cariocas" como uma totalidade determinada. Destaco que há diferenças essenciais entre as favelas e também em suas formações sociais internas. Entretanto, considero plausível apontar que, historicamente, uma construção discursiva sobre "as favelas" e "o problema" reproduz a composição de uma administração es tadual específica em termos de urbanização, infraestrutura urbana e políticas públicas (BURGOS, 1998; VALLADARES, 2005).
} 
Dossiê | Incerteza e suspensão: notas sobre a vida material e política da infraestrutura no cotidiano da favela Santa Marta/RJ (MANO, Apoena)

laboratório" e "favela modelo". Nesta perspectiva, considero que a favela pode ser percebida como uma margem do estado ${ }^{8}$.

Apoiado sobre a proposta de interpretação a partir do arcabouço analítico das infraestruturas urbanas, pretendo debater formas de gestão do cotidiano em meio a situações de precariedade a partir da conjuntura mencionada. O objetivo é analisar como as ações do Estado são percebidas pelas populações da favela, com as políticas públicas e seus diferentes circuitos em suas formas de agenciamento em "espaços de indeterminação" ${ }^{9}$. Para tanto, utilizarei reportagens veiculadas pela mídia e trechos de etnografias realizadas na favela Santa Marta durante o referido período para complementar a descrição de relatos anotados em meu próprio caderno de campo $^{10}$. Após uma breve descrição da favela com vistas a identificações e segmentações internas em função da infraestrutura, o artigo se estrutura a partir de três eixos: os agenciamentos em torno das obras inacabadas do Conjunto Habitacional; as incertezas e efeitos relacionados à regularização de serviços de eletricidade na favela; a percepção no contexto presente sobre o contraste entre promessas e suspensões. Ao final, considerações são elaboradas sobre o governo de populações promovido por um Estado moderno que racionalmente produz vidas expostas à morte.

\section{Favela Santa Marta: da ladeira ao pico}

A Praça Corumbá é o local de interseção entre o bairro de Botafogo, na Zona Sul do Rio de Janeiro, e a subida para a favela Santa Marta. A partir dali, olhando em direção à favela, pode-se observar uma movimentada rua, com diversos camelôs, vendedores

\footnotetext{
8 As "margens do Estado" não são demarcadas a partir de aspectos exclusivamente geográficos: o descolamento de um modelo es pacial de centro e periferia foi acontecend o na medida em que se percebia que várias ideias a respeito de "margens" eram basea das em relações entre soberania eformas de poder disciplinar, onde determina dos territórios são percebidos como locais de experimentações situacionais e regimes de exceção (DAS; POOLE, 2004).

9 Em um trabalho sobre grupos populares em ocupações, Birman, Fernandes e Pierobon (2014) relacionam direito de acesso à cidade à indeterminação pelo quadro de urbanização da cidade. Este cenário intensifica a gestão diferencial dos ilegalismos pelo peso que adquire o tráfico de drogas, juntamente com a ilegibilidade que tem caracterizado as políticas e ações da governamentalidade sobre as formas de vida e de trabalho na região.

10 Minha inserção na favela é motivada pela investigação sobre a percepção local do Es tado a partir de des dobramentos relacionados a turismo, violência urbana e formas de resistência. Entretanto, dimensões relacionadas à urbanização e a infraestrutura destacam-se em uma metodologia voltada ao cotidiano principalmente por tratar-se de um momento de expectativas frustradas.
} 
Dossiê | Incerteza e suspensão: notas sobre a vida material e política da infraestrutura no cotidiano da favela Santa Marta/RJ (MANO, Apoena)

informais de frutas, salgados, eletrônicos, ferramentas, roupas e produtos de vários tipos. Também chama a atenção um intenso sobe-e-desce de pessoas indo trabalhar, levando crianças à escola, saindo a seus afazeres cotidianos. Entre elas, percebe-se a inconstante circulação de poucos carros e motos. Em geral, as motos circulam para outros lugares da cidade a partir do ponto de moto-taxi. Um pouco mais à frente, nesta rua, fica o Bar do Tota, um dos bares mais freqüentados pelos moradores. Olhando mais para cima, pode-se ver a favela surgindo por trás de uma grande árvore. Por ser um território estreito e íngreme, é possível se analisar as fronteiras físicas da favela: à direita, uma região delimitada por trilhos e cabos de aço, por onde funciona o Plano Inclinado, também conhecido como "bonde", que transporta as pessoas verticalmente por 5 estações acima na favela; ao centro, uma quantidade incrível de casas sobrepostas - de diferentes tamanhos, cores e composições; à esquerda, entre as casas, chama a atenção uma construção incompleta de um prédio, e; na parte mais alta, algumas construções de formato diferente limitadas por uma enorme extensão de mata que cresce para cima, por onde continua o morro até o Mirante Santa Marta. Certa vez, eu estava nesta praça conversando com uma moradora sobre a distribuição das casas na favela. Ela me ofereceu uma interessante explicação relacionando as condições de vida das pessoas à sua localização pelo à infraestrutura da favela. De acordo com sua interpretação, a favela é dividida em três partes: "ladeira", "parte baixa" e "parte alta".

A ladeira é o curto trecho que liga a Praça Corumbá até o "escadão" que marca o início da favela. Ela me disse que, por ser uma condição de vida muito diferente da estabelecida nas casas e vielas no morro, "por mim, nem dá pra considerar isso ai como favela". Em geral, moradores em condições econômicas favoráveis conseguem mudarse para essa regiãoe, em muitas oportunidades, ao invés de vender suas casas na favela, preferem alugar para contribuir com o financiamento da casa nova na "ladeira". As pessoas da parte baixa seriam a "classe média" da favela. Esta dimensão valorativa foi proposta pela moradora com destaque às possibilidades de mobilidade e circulação pela favela. Por estarem próximos ao "asfalto", moradores da parte baixa não dependem do Plano Inclinado para se locomoverem pela favela até suas casas. Esta característica configura benefícios diversos, como facilidade para transporte de material e realização de obras estruturais em suas casas, acesso próximo à Associação de Moradores para buscar suas correspondências, facilidade para chegar a suas casas sem o "bonde" e 
Dossiê | Incerteza e suspensão: notas sobre a vida material e política da infraestrutura no cotidiano da favela Santa Marta/RJ (MANO, Apoena)

melhores condições para transitar entre favela e asfalto. Viver na parte alta da favela seria "o mais difícil", de acordo com esta explicação. O "pico" é um local com maiores dificuldades para habitação, considerando principalmente que a região foi desconsiderada dos últimos planos de urbanização. Perguntei o motivo desta diferenciação e ela disse que "é porque havia um projeto de remover as pessoas dali". Ela não explicou as razões disto ${ }^{11}$, mas continuando seu relato sobre as diferenças internas na favela, ela mencionou que há diferenças nas formas de vida entre as pessoas que moram na parte alta e as do pico, configurando uma diferenciação que ela definiu argumentando que "o pessoal de cima é que vive de verdade no sufoco. Se for comparar com o pessoal aqui de baixo, é favela raiz e favela nutella mesmo".

Ao circular pela parte do pico da favela, é realmente fácil perceber o contraste entre este local e o restante da favela. Diversas casas são construídas em madeira, a quantidade de lixo pelas vielas é maior do que no restante da favela, o calçamento é precário e há pouca iluminação durante a noite. O último processo de políticas de urbanização na favela foi interrompido de acordo com a localização da ultima estação do Plano Inclinado. O pico fica mais acima, e é reconhecidamente a "área mais sacrificada do morro". Ironicamente, foi por ali que teve início a construção de casas na favela. Então, apesarde algumas casas seremmaiores, também são mais antigas. Outras casas são construídas em madeira, constituindo uma infraestrutura interna precária em muitas não há banheiro, água na torneira ou eletricidade. A caminhada até o topo é bastante dificultada, mesmo com o Plano Inclinado, o que leva as pessoas a muitas vezes utilizarem a saída pela parte de cima, que dá acesso ao bairro de Laranjeiras.

Moradores da favela historicamente lutam e reivindicaram pela requalificação e manutenção das casas desta área da favela. Ao sair do bonde na última estação, logo chama a atenção uma grande faixa onde se pode avisar uma faixa preta com o termo "gentrificação". Um outro morador me explicou que o pico foi "deixado de lado" pelo projeto de urbanização e, naquela época, houve muitos rumores sobre aquela ser uma

\footnotetext{
11 Menezes (2015) comenta sobre rumores na favela durante este período. Em relação a contínuas mudanças no plano de urbanização da favela, moradores do pico temiam a possibilidade de serem removidos do local. Embora o Governo justificasse que as condições que caracterizava m uma "área de risco", os residentes da área temiam que futuramente fosse construído um hotel no local.
} 
Dossiê | Incerteza e suspensão: notas sobre a vida material e política da infraestrutura no cotidiano da favela Santa Marta/RJ (MANO, Apoena)

área de interesse do empresário Eike Batista ${ }^{12}$ - onde as pessoas seriam removidas e o caminho vindo por Laranjeiras seria estendido "por cima" até ali. "Isso aqui deixaria de serfavela, sabe? la virar outra coisa - Hotel Eike Batista, sei lá", me disse. Ele mencionou que o prédio de moradias na parte esquerda do morro, cuja construção foi interrompida "logo que tudo acabou" serviria de moradia, em especial, para pessoas que seriam removidas desta região da favela. Com isto, relaciona a falência de Eike e do Estado à interrupção do projeto do prédio.

\section{As obras interrompidas do Conjunto Habitacional}

Na parte esquerda da Favela, em meados de 2011, foi iniciada a construção de um prédio de moradias populares, que seria oferecido a pessoas que habitavam "casas em situação precária", como afirmava o Governo do Estado - em geral, pessoas que moravam nas casas do pico da favela. Estes moradores foram orientados a realizar um cadastro junto à prefeitura para oficializar a promessa das casas. A partir daí, deveriam aguardar o término da obra para a realocação neste local. A obra teve início. Muito material foi levado ao local. Muitos trabalhadores exaustivamente trabalhavam no projeto. A estrutura começou a crescer e ser percebida. Então, a obra parou.

Devido a narrativas de crise financeira do Governo do Estado ainda antes da Copa do Mundo, a continuidade das obras foi interrompida e sem previsão de retorno - assim como a promessa de moradia às pessoas em situação precária. Em seguida, o decreto de "Estado de Calamidade Pública" pelo Governo do estado ocasionou desesperança ainda maior. Passando pelo local, é possível observar que no entorno da região há muitas construções onde pessoas vivem em condições de extrema precariedade estruturas frágeis, de madeira, com tetos por onde atravessa a chuva, sem instalação de eletricidade, água e esgoto, sem banheiro, em terreno bastante irregular e cercado por

\footnotetext{
12 Como aponta Gutterres (2016), o empresário Eike F. Batista da Silva foi considerado em 2012 o 3 o homem mais rico do Brasil. Seu grupo EBX expandia os investimentos em mineração, no setor imobiliário, na indústria naval, em logística e petróleo. Nesse ano, a cidade do Rio de Janeiro era retratada pela mídia corporativa como um grande loteamento dos investimentos do empresário, e provavelmente pela ascensão de sua figura, os rumores sobre hotéis no alto de favelas e a aquisição deáreas próximas a elas para empreendimentos turísticos foram recorrentes nas narrativas de moradores. Atual mente está preso por corrupção, o que pode ser interpretado de maneira emblemática em relação a todo este processo.
} 
Dossiê | Incerteza e suspensão: notas sobre a vida material e política da infraestrutura no cotidiano da favela Santa Marta/RJ (MANO, Apoena)

lixo, facilitando alagamentos. Para evitar o acúmulo de pagamento de aluguel, diversas pessoas abandonaram suas casas anteriores e preferiram viver provisoriamente naquelas condições para aguardar a finalização das obras. Entretanto, a suspensão das obras reconfigurou o provisório em perene. Foi comentado por outros moradores que as pessoas nestas condições "vivem como a favela era 50 anos atrás". Isso suscita reflexões sobre o trabalho do tempo na vida das pessoas (DAS, 1999), onde promessas de "avanço" na verdade afetou alguns sujeitos de maneira a "voltar" no tempo.

Em diversas oportunidades, conversando com pessoas que considero lideranças locais, ouvi relatos, rumores e indicativos de que há interesse em "ocupar" aquele local: para realizar algum projeto cultural, ou mesmo para as pessoas morarem ali. Apesar de a construção estar "somente no esqueleto" e "sem acabamento", seria possível realizar ajustes, como coberturas, portas provisórias e instalações irregulares de água e eletricidade para utilização e permanência no local. Posteriormente, descobri que no início de 2018 aconteceu uma tentativa de ocupação pelos próprios moradores que estão vivendo na região. Policiais militares perceberam a ação destas pessoas. Os ocupantes do prédio foram retirados de maneira bastante violenta e agressiva. Como retaliação, as casas de madeira no entorno do prédio que estavam sendo habitadas anteriormente foram destruídas. Muitas pessoas ficaram desalojadas até que conseguissem reconstruir suas casas.

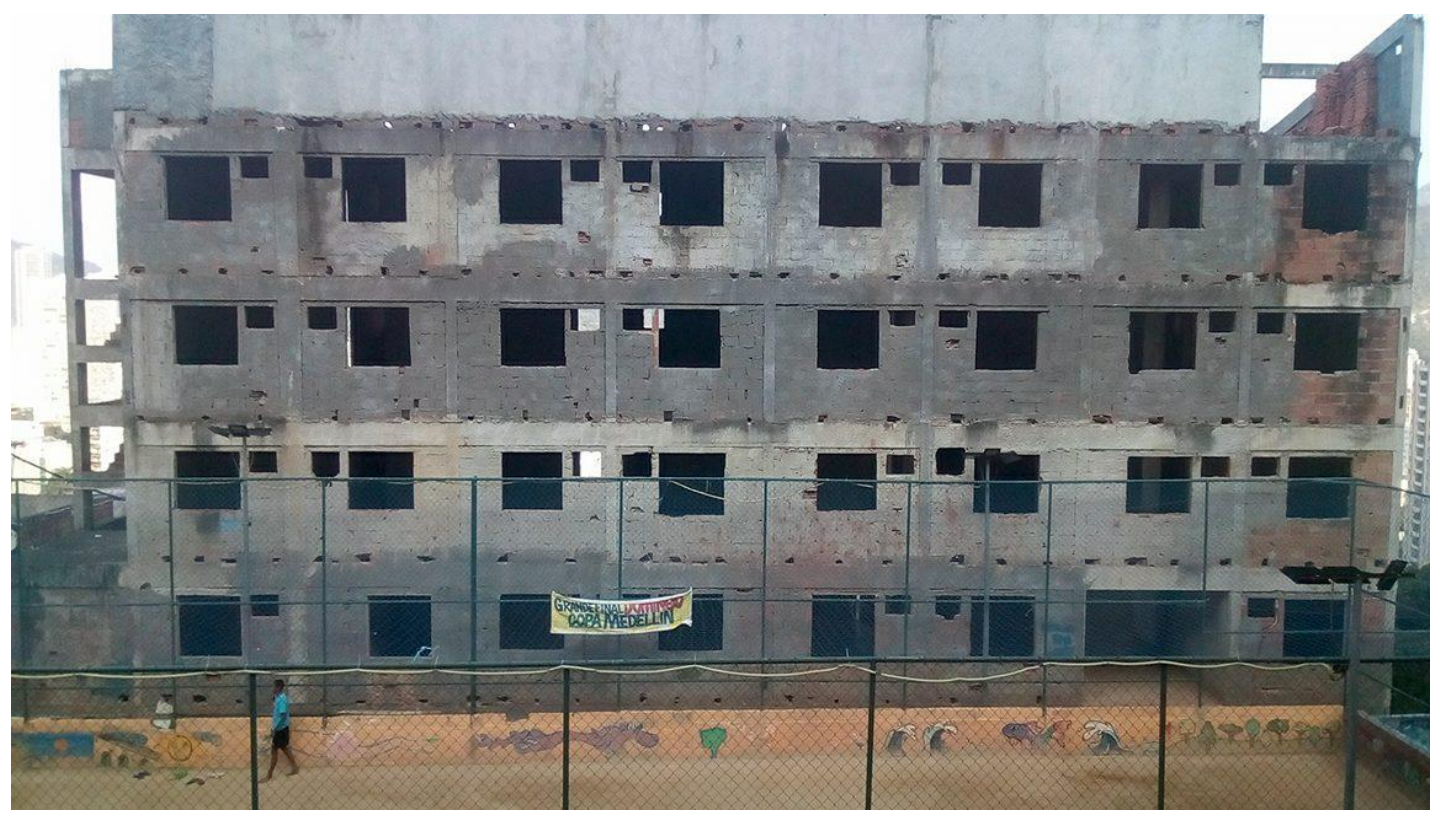

Figura 1 - Parte da construção interrompida do conjunto habitacional. Fonte: Acervo do autor 
Dossiê | Incerteza e suspensão: notas sobre a vida material e política da infraestrutura no cotidiano da favela Santa Marta/RJ (MANO, Apoena)

Em junho de 2018 foi divulgada pelo noticiário televisivo RJTV1 uma reportagem sobre a suspensão da obra ${ }^{13}$. O produtor foi Thiago Firmino, um empreendedor local e guia de turismo articulado com a Agência de Notícias das Favelas e a própria Rede Globo. A produção é uma denúncia sobre a situação do prédio, com filmagens do interior da construção inacabada e entrevistas com moradores que compartilham suas impressões sobre a interrupção da obra. Nas imagens do interior do prédio, pode-se notar uma situação expressivamente degradada: muito mofo e paredes estufadas, além da descrição de um cheio muito ruim. Os jornalistas da emissora referem-se com indignação ao investimento em um projeto não concluído: “o dinheiro está enterrado ali".

O relato dos moradores é bastante intenso. Há alguns anos, após uma forte chuva sobre a cidade, Antônia Cerqueira de Lima perdeu "tudo que tinha" e também um filho, soterrado no barraco em que viviam. Convivia com a expectativa da "melhoria de vida" até a interrupção das obras: "Ela até agora não ganhou nada e convive com a promessa de ganhar um apartamento", conta Thiago. Rosângela Maria Dias, que vive há 40 anos na favela, tinha os documentos das promessas nas mãos e "segue esperando a conclusão do prédio". Sobre as condições em que está vivendo, outra moradora relata que "chove mais dentro do que fora, e meu esposo doente com começo de AVC fica dentro de casa. A gente precisa pegar um balde pra não ficar morrendo".

Thiago menciona que a situação de interrupção das obras influenciou também seu próprio cotidiano: sua avó também recebeu o documento que garantia a promessa de viver em um dos apartamentos do prédio. Entretanto, ela faleceu em 9 de Maio de 2012, e "infelizmente hoje ela já não está mais aqui e não pode nem desfrutar do direito que ela tinha, que é ter uma casa". Ele descreve o acontecimento enquanto filma o documento assinado - que supostamente deveria garantir o compromisso do Estado. Ao longo da reportagem, Firmino relata situações que descrevem características de um cotidiano de exceção. Entre outros relatos sobre suas expectativas, moradores mencionam que: 
Dossiê | Incerteza e suspensão: notas sobre a vida material e política da infraestrutura no cotidiano da favela Santa Marta/RJ (MANO, Apoena)

"Perdemos a esperança. Foram prometidos apartamentos para quem tinha casa de madeira e morava em área de risco. Estamos em risco até hoje né, meu filho?; "A gente se sente humilhada, né? Porque prometem e não cumprem. Até se fosse um material para consertar a minha casa (de madeira) eu queria"; "É muito importante. Muito mesmo. Do fundo do coração. To pedindo pelo amor de Deus, porque eu quero que o sonho do meu esposo se torne realidade". (RJTV1, 2018)

O reconhecimento destas características e a utilização de termos como "em risco", "se sentir humilhada" e "pedir pelo amor de deus" pode produzir efeitos sobre a subjetividade destes sujeitos. Em sua tese de doutorado, Pierobon (2018) reflete sobre o cotidiano precarizado de Leonor, moradora de uma Ocupação na região Portuária do Rio de Janeiro. Entre diversos acontecimentos, relata um evento onde tenta interpretar os efeitos sobre a subjetividade de sua interlocutora que, para receber benefícios sociais, é levada a assinar um documento chamado "atestado de miserabilidade" ${ }^{14}$. Neste momento, o Estado inscreveu sua assinatura (DAS, 2004) na subjetividade e na constituição de pessoa de Leonor ${ }^{15}$. Do mesmo modo, o cotidiano destas pessoas em situação de suspensão afeta sua subjetividade, onde expectativas são mobilizadas em função de um documento que deveria garantir condições dignas de moradia em algum momento futuro. Entretanto, seu presente é produzido pelo trabalho do tempo a partir de uma suspensão caracterizada por dor, precariedade e expectativas frustradas (DAS, 1999).

É possível considerar os efeitos da infraestrutura no cotidiano a partir dos relatos de pessoas que já vivam em condições muito desfavoráveis no pico da favela e, devido à suspensão das obras do conjunto habitacional, tiveram outros tipos de efeitos sobre sua subjetividade e cotidiano. Chamo atenção aos efeitos da exclusão física da infraestrutura urbana constituindo formas de sofrimento, que marca aqueles afetados

\footnotetext{
${ }^{14}$ A inscrição no Cadastro Único para Programas Sociais do Governo Federal foi realizada para possibilitar o recebimento do auxílio disponível pelo programa Bolsa Família. Apesar da contrariedade sobre o documento, em um momento posterior a interlocutora se percebeu acometida e influenciada pelo documento para refletir sobre sua situação cotidiana: "Hoje sim eu quero o bolsa família, porque antes eu não era uma pessoa miserável, mas hoje sim, quando eu olho pra a minha vida eu sei que eu sou uma pessoa miserável!" (PIEROBON, 2018: 119)

15 Nos termos de Veena Das (2004), "assinaturas do Estado" são o registro das múltiplas formas de presença do Estado, em sua face legal-burocrática, como diz a autora, "incorporada nas regras e regulações de espaços e atividades, nos seus dispositivos, agentes e procedimentos pelos quais elas se efetivam". Operam como uma força gravitacional das práticas e dos modos como os atores lidam com a situação e seus pontos de fricção, bem como "dos recursos mobilizados para contornar, resistir, enfrentas e, no final das contas, sobreviver nesses lugares". (apud TELLES, 2015: 65)
} 
Dossiê | Incerteza e suspensão: notas sobre a vida material e política da infraestrutura no cotidiano da favela Santa Marta/RJ (MANO, Apoena)

e seus "corpos precarizados", onde podem ser percebidas "vulnerabilidades constitutivas das assimetrias de poder e dominação que ordenam a cidade" (FRANGELLA; RUI, 2018) e, fundamentalmente, o questionamento de noções de cidadania e direitos sociais a determinadas populações. Inspirado pelo trabalho de Pierobon (2018), percebo a importância de observar como estas pessoas continuam a habitar um "mundo de dor e devastação" e como essas dores "permanecem vivas na vida cotidiana, percebidas e interpretadas como práticas de exceção no interior da vida ordinária". Desta maneira, os moradores da favela, afetados pela ação contínua do Estado, podem ter sua vida ordinária percebida como um lugar de vulnerabilidade a projetos de poder estatais e suas diversas normatividades regimentais.

No fim da reportagem, a jornalista da emissora prepara o ambiente para informa $r$ uma "notícia triste": Dona Rosangela, uma das entrevistadas, sofreu um infarto alguns dias após a produção da reportagem e não resistiu, vindo a falecimento. Seu esposo, Manuel Izidoro, um dos líderes comunitários mais antigos do morro, continua morando na casa "cheia de buracos e infiltrações". Outro jornalista que acompanhava a transmissão menciona que a previsão sobre a conclusão das obras é "muito ruim". Ele explica que há várias formas de financiamento, como do Governo Federal ou da Caixa Econômica Federal, mas este prédio foi construído com investimento do Governo do Estado: "e nesta crise do governo a primeira coisa que se corta é o investimento. $O$ projeto desta construção foi cortado e não há previsão para a retomada da obra". As pessoas que estão aguardando o término da obra e entrega das moradias estão na fila deste projeto e, por isso, estão impossibilitadas de inscrever-se em outro programa de moradia popular. Ao final, uma afirmação sobre as pessoas retratadas nesta reportagem é bastante descritiva e contundente em relação a um cotidiano de indeterminação sob um contexto de suspensão: "por isso é tão duro para elas, viver ao lado de suas expectativas".

\section{Interrupções e a distribuição de eletricidade}

Durante minhas atividades na favela, é bastante freqüente que eu precise subir as escadas da favela a pé, porque a falta de eletricidade interrompe o funcionamento do Plano Inclinado. Como principais efeitos relacionados a essa interrupção, percebo 
Dossiê | Incerteza e suspensão: notas sobre a vida material e política da infraestrutura no cotidiano da favela Santa Marta/RJ (MANO, Apoena)

principalmente como esta habitual eventualidade atrapalha meu planejamento de horários, acarretando o atraso para compromissos pelo gasto maior de tempo enquanto subo pelas escadas ao invés de utilizar o bonde - e também o cansaço após subir trechos de degraus irregulares. Estas experiências ajudam a pensar sobre o cotidiano de pessoas que contam diariamente com a utilização do Plano Inclinado. É possível refletir sobre as alterações de temporalidade influenciadas pela existência e funcionamento de infraestruturas específicas. Neste caso, dependendo do funcionamento ou suspensão da distribuição de eletricidade e, consequentemente, da mobilidade permitida pelo "bonde", há diferentes efeitos produzidos no cotidiano. Em todas as vezes que preciso subir caminhando, tento abordar outras pessoas e falar sobre o assunto - (para não perder tempo). Geralmente, escuto reclamações relacionadas ao fato de que "isso acontecer toda hora" e que "atrapalha a nossa vida, que já é difícil". Neste caso, apesar do projeto ter sido concluído, é interessante pensar nas condições e provocações relacionadas às expectativas e incertezas relacionadas à continuidade do funcionamento da infraestrutura, assim como nos efeitos da interrupção.

Certa vez, em uma ocasião onde eu subia os degraus conversando com um morador, ele comentou comigo sobre suas incertezas em relação ao funcionamento do Plano Inclinado. Ele disse que os moradores dependem muito do funcionamento do Plano para subir até suas casas, e me questionou "até quando isso vai funcionar?". Fiquei um pouco surpreso com essa questão, pensando que não faria sentido o bonde deixar de funcionar, por causa do valor de investimento na obra e, principalmente, da quantidade de pessoas que utilizam todos os dias. Entretanto, a resposta dele me deixou um pouco consternado: "Tanto faz quanto gastaram. Manter funcionando também sai caro. Você viu que os teleféricos da Providência e do Alemão já não funcionam mais, né?". Essa é uma grande preocupação na favela porque, de acordo com ele, "não se sabe qual será a postura e o interesse dos próximos governos". 


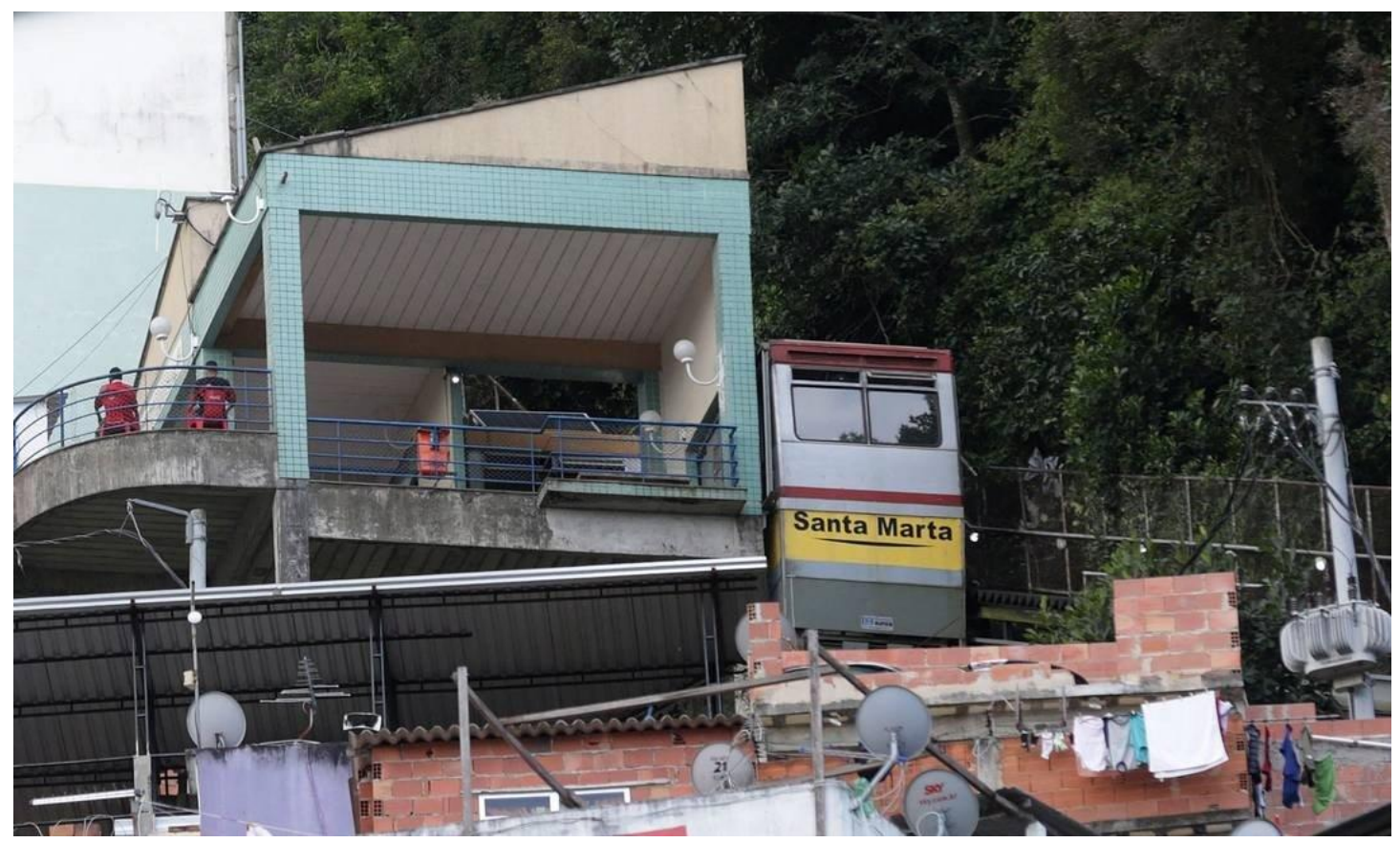

Figura 2 - Bonde do plano inclinado parado na estação fechada. Fonte: Marcio Alves (O GLOBO, 2017)

Uma reportagem divulgada pelo jornal O Globo em 2017 denuncia que, em diversos momentos, o bonde tem o funcionamento interrompido por "atrasos no pagamento pela prefeitura das verbas para o pagamento do contrato". Além de problemas condicionais, como dificuldade para o transporte de cargas e o recolhimento do lixo da favela, o presidente da Associação de Moradores manifesta sua indignação: "O Santa Marta é a comunidade mais inclinada do Rio. São 780 degraus até o topo da favela. Como faz para subir e descer isso tudo todos os dias?" (O GLOBO, 2017). É bastante crítico perceber como a favela ainda é permeada por incertezas sobre o funcionamento e manutenção de serviços básicos. Seria apropriado comparar com hipotéticas preocupações de outras partes da cidade sobre o funcionamento do serviço de ônibus, por exemplo. Sobre o Plano Inclinado, é um fator crítico pensar em sua interrupção principalmente porque sua utilização está relacionada de maneira fundamental à qualidade de vida e mobilidade das pessoas da favela.

O Plano Inclinado foi inaugurado em 2008. É assertivo afirmar que o equipamento de transporte facilita a vida dos moradores que vivem em locais próximos às estações, percorrendo em cerca de dez minutos os 340 metros de extensão inclinada. Contudo, no planejamento original, realizado em conjunto com a Associação de Moradores do 
Dossiê | Incerteza e suspensão: notas sobre a vida material e política da infraestrutura no cotidiano da favela Santa Marta/RJ (MANO, Apoena)

Santa Marta, haveria um "bonde" de cada lado da favela e interconexões horizontais entre eles, conforme relatou outro morador. Na prática, o projeto foi "concluído" com somente a construção dos trilhos no lado direito da favela. Sobre as mudanças em relação ao planejamento e o que foi de fato construído, o prefeito César Maia não autorizou a construção do Plano Inclinado do lado esquerdo porque seria "desnecessário", conforme o relato. Com efeito, pode-se dizer que o projeto do Plano Inclinado, ainda que muito utilizado pelos moradores, não foi de fato concluído em relação a seu planejamento original e as expectativas dos moradores. Dando continuidade à conversa, perguntei sobre como era o cotidiano e a vida na favela antes do Plano Inclinado. O morador comentou, enquanto seguíamos subindo, que se para adultos a locomoção pela favela já era dificultada, no caso de pessoas com dificuldade de locomoção, como gestantes, pessoas com crianças de colo e idosos, transitar pela favela e também pelo restante da cidade era praticamente impossível. Respondendo à minha questão, ele comentou que estas pessoas "saíam bem menos da favela", e precisavam planejar muito bem suas atividades durante a semana.

Neste debate que relaciona infraestrutura, cotidiano e formas de governo, penso ser interessante salientar um exemplo na favela onde a interrupção da distribuição de eletricidade se relaciona a outra dimensão de ações do Estado: a segurança pública. $O$ transformador que distribui energia elétrica por toda a favela fica bem próximo à entrada principal, perto da Praça Corumbá. Em eventos de ação policial e disputa territorial, quando freqüentemente ocorrem confrontos armados e tiroteios ${ }^{16}$, esta "caixa de luz" é "acidentalmente" atingida por projéteis, interrompendo o recebimento de energia elétrica de grande parte das pessoas da favela. Por causa destes tiroteios, as pessoas ficam sem eletricidade em suas casas, além do Plano Inclinado também deixar de funcionar. É importante ressaltar que a interrupção de um serviço básico pode trazer consequências desgastantes, como sensação de calor, o desperdício de alimentos e a interrupção do comércio local. Em outra ocasião, agentes da Polícia Militar não autorizaram a entrada na favela de funcionários da Light para restabelecer a distribuição de energia elétrica. Foi necessário que um grupo de moradores se agrupasse. Para reverter a situação, os moradores não deixaram o carro ir embora e acompanharam a

\footnotetext{
16 Des de a inauguração da UPP Santa Marta em 2008 até os tiroteios cessaram de maneira significativa. A partir de 2015, tornam-se cada vez mais freqüentes.
} 
Dossiê | Incerteza e suspensão: notas sobre a vida material e política da infraestrutura no cotidiano da favela Santa Marta/RJ (MANO, Apoena)

equipe de funcionários em sua locomoção pela favela até que o serviço fosse finalizado. Relatos apontam que, no momento em que moradores acompanhavam a situação, alguns policiais permaneceram hostilizando pessoas, agredindo verbalmente e até jogaram uma pequena bomba caseira para assustar moradores e impedir o serviço.

É possível discutir no âmbito da infraestrutura sobre os efeitos da regularização do fornecimento de eletricidade sobre os moradores da favela. Um dos principais efeitos das UPPs foi um novo tipo ordenamento dos territórios pacificados, incluindo a regularização do fornecimento de eletricidade e de água, assimcomo do funcionamento dos estabelecimentos comerciais (MENEZES, 2015). Ainda que o projeto da UPP tenha repercutido a ideia de que a "pacificação" traria "importantes conquistas para o exercício da cidadania" nas favelas, questionamentos de moradores relacionados a efeitos contraditórios desta "chegada da cidadania" referem-se aos altos custos relacionados à regularização de distribuição e manutenção de serviços básicos, como distribuição de energia elétrica, esgoto, etc. A autora relata o trecho de uma conversa com uma moradora que questiona a narrativa de que a UPP levaria a cidadania às favelas porque "porque todos nós já éramos cidadãos antes mesmo da UPP chegar. Todos nós já pagávamos impostos de várias outras formas" (MENEZES, 2015, p. 47). De forma geral, é um questionamento recorrente a cobrança pelos serviços nas favelas serem semelhantes às taxas pagas por moradores do "asfalto", ainda que seja percebido um evidente contraste na distribuição e manutenção dos serviços. A infraestrutura de saneamento dessas áreas não é o mesmo e o fornecimento também não é igualmente distribuído, uma vez que o fornecimento de água e eletricidade no morro é interrompido com frequência. Especificamente sobre as contas de luz, é necessário destacar que o aumento relaciona-se com a instalação de um equipamento de medição que gera muita desconfiança por parte de moradores ${ }^{17}$. Em seu trabalho etnográfico, Menezes (2015) traz relatos de moradores que apontam que esse aumento constante

\footnotetext{
17 Diversos moradores da favela estabelecem uma associação entre as contas altas e o fato da medição do consumo de energia elétrica no Santa Marta ser realizado através de chips. Como apontam Cunha e Mello (2011, p. 386), em 2010, a Light instalou na favela "um sistema de telemediação para todas as ações, através do qual a companhia faz cortes e ligações diretamente da empresa e controla o consumo residencial sem precisar medir o relógio todo mês, como fazia anteriormente". Tal sistema já foi investigado pelo Ministério Público, que indicou que ele parasse de ser utilizado, mas os chips ainda continuam sendo usados em diversas favelas e vêm sendo constantemente criticados pelos moradores.
} 
Dossiê | Incerteza e suspensão: notas sobre a vida material e política da infraestrutura no cotidiano da favela Santa Marta/RJ (MANO, Apoena)

gera uma grande ansiedade, já que não permite que cada família possa prever quanto terá que gastar a cada mês:

\begin{abstract}
"A Light, se você não pagar no dia, ela humilha você, ela corta a sua luz e você fica no escuro... Quem está no mundo externo, de fora, vê na internet lá, e acha que o colorido do morro está bonito. $O$ jornalista quebra a cabeça dele lá, faz um floreio danado para escrever que está tudo lindo no morro. Mas aqui nós estamos no clima, no dia a dia, a realidade é outra. Quem está de fora, maravilha. Por enquanto não, não está essa coisa toda não. Eu não sou pessimista não. Eu sou até otimista. Mas a realidade está difícil. As contas estão chegando num valor cada mês mais alto e quem vive de salário mínimo daqui a pouco não vai conseguir pagar não!". (MENEZES, 2015)
\end{abstract}

Aqui, vale a reflexão sobre os reflexos da regularização da infraestrutura de distribuição de eletricidade e cobranças de serviços relacionados ao que é referido neste trecho como "humilhação", devido ao custo adicional influenciar suas condições de sobrevivência financeira. A quebra da informalidade relacionada à infraestrutura traz questionamentos sobre uma "realidade difícil", onde "daqui a pouco não vão conseguir pagar". Desta forma, fatos relacionados à infraestrutura e benefícios ao território acabam por prejudicar pessoas que vivem nestes locais. Eventualmente, o aumento do custo de vida causa a expulsão destas pessoas para residir em outros lugares. É pertinente refletir como políticas de infraestrutura são relacionadas à "cidadania" e ao "direito à cidade", mas o acompanhamento de políticas sociais torna-se imprescindível para que se evite a substituição de grupos que ocupam determinados espaços.

Diversas dimensões da vida na favela se relacionam ao funcionamento do "bonde", produzindo efeitos cotidianos de temporalidade e subordinação. A partir de formas e condições de funcionamento ditadas pelo Estado, a partir de uma "mecânica do poder" aqui relacionada à infraestrutura, o cotidiano das pessoas está submetido à influência, obediência e disciplina ao horário de funcionamento da infraestrutura. É fundamental também refletir nos mesmos termos sobre os efeitos da formalização de serviços de distribuição de eletricidade e as consequências disto sobre as condições de vida das populações. Compreendendo que "materiais e tecnologias de infraestruturas não são politicamente neutros" (ANAND, 2017b), e a regularização dos serviços e início das cobranças produzem mudanças instituídas pelo Estado nas condições de vida das populações. A interpretação de determinados moradores de determinadas partes da 
Dossiê | Incerteza e suspensão: notas sobre a vida material e política da infraestrutura no cotidiano da favela Santa Marta/RJ (MANO, Apoena)

cidade sobre a implementação de direitos sociais é permeada de dúvidas e desconfianças pela sensação de marginalização pelo Estado (ROY, 2005; TELLES, 2015).

\section{Maquiagem, esculachos e incompletude}

No dia 8 de julho de 2013, moradores do Santa Marta organizaram um protesto pelas ruas de Botafogo para expressar sua insatisfação em relação à distorção que percebiam entre a "imagem vendida da favela e a experiência cotidiana no morro". Como relata Menezes (2015), no texto de convocação para a reunião era dito:

"Queremos Favela Modelo de verdade e não maquiagem! Tá cansado de pagar conta de luz muito alta? Cansado de ter que subir a pé por causa das más condições do bonde? Cansado de pagar esgoto quando ainda temos valas abertas? Vivendo a insegurança de ser removido? Então vem pra rua! O Santa Marta vai descer e reivindicar pra ser uma FAVELA MODELO de verdade!"

Ao comparar os termos "Favela Modelo de verdade" e "maquiagem", o texto de convocação para o protesto torna evidente uma importante hipótese sobre aquele momento. Eram freqüentes os comentários a respeito das intervenções urbanas serem planejadas por objetivos distintos à alteração da qualidade de vida de populações em territórios específicos. Aponta-se que "revitalização" de determinados espaços teria por objetivo a formulação de um discurso externo a partir da narrativa das obras. Em outras palavras, a finalidade das intervenções não seria beneficiar moradores das favelas, mas produzir sobre a cidade uma sensação de que "o problema da favela estava resolvido"18.

Novas infraestruturas são promessas feitas no presente sobre o futuro, e quando suspensas no presente, elas simbolizam as ruínas de um futuro antecipado e os resíduos de uma modernidade antecipada (APPEL, ANAND \& GUPTA, 2015). Tomar esta reflexão para analisara produção urbana neste período torna-se pertinente para interpretar o

\footnotetext{
18 Muitos representantes locais da favela Santa Marta argumentavam que a narrativa de "favela modelo" era uma "grande vitrine" que servia ao Estado e a mídia, em ação conjunta, para "atrair holofotes" enquanto aconteciam em outras favelas eventos de violência, abandono e arbitrariedade - como o caso do pedreiro Amarildo assassinado e ocultado pela Polícia Militar em 14 de Julho de 2013, entre vários outros. Em diversas oportunidades, conversando sobre os últimos eventos, moradores me trouxeram percepções relacionadas a esta hipótese, mencionando exemplos de como a falta de diálogo entre políticas públicas e a população da favela produz intervenções com efeitos contraditórios e muito prejudiciais para a favela.
} 
Dossiê | Incerteza e suspensão: notas sobre a vida material e política da infraestrutura no cotidiano da favela Santa Marta/RJ (MANO, Apoena)

significado que obras de infraestrutura em favelas representam em um modelo narrativo relacionado à modernidade - não somente da favela, mas dela como parte da cidade. Principalmente porque, em interpretações habituais do senso comum, as favelas representariam um tipo de "desordem urbana", cuja existência simboliza a impossibilidade de se conceber uma cidade "urbanisticamente organizada $e$ racionalmente funcional" (MAGALHÃES, 2013). Assim, narrativas sobre projetos de infraestrutura em favelas podem compor um processo político e ressignificativo do imaginário coletivo da cidade. Passados dois anos após o término dos Jogos Olímpicos, os contrastes narrativos das diversas suspensões e interrupções - como o nãofuncionamento do teleférico do Complexo do Alemão - podem ser uma importante chave interpretativa para se analisar o momento anterior e também o que pode estar por vir no contexto de produção de cidade.

No final de 2018, moradores reuniram-se mais uma vez na Praça Corumbá. Desta vez, o objetivo era denunciar a constante sensação de desmonte relacionada às políticas públicas dos últimos anos. Na convocação, foram destacados questionamentos sobre a ação policial na favela, que entre diversas formas de violência estaria entrando em casas de moradores sem autorização. Além disto, a infraestrutura da favela foi evidenciada como uma importante fonte de preocupação: moradores relatam problemas na distribuição de eletricidade e água, prestada pelas companhias Light e Cedae, respectivamente. O funcionamento irregular do Plano Inclinado, interrompido freqüentemente em função da "necessidade de manutenção" também preocupa os moradores em relação a sua suspensão permanente. Após a concentração na praça, os moradores interromperam parcialmente a circulação de carros na Rua São Clemente e caminharam pelo bairro de Botafogo. Entre as denúncias, a fala que mais ecoou entre os manifestantes foi "chega de esculacho na favela!". 


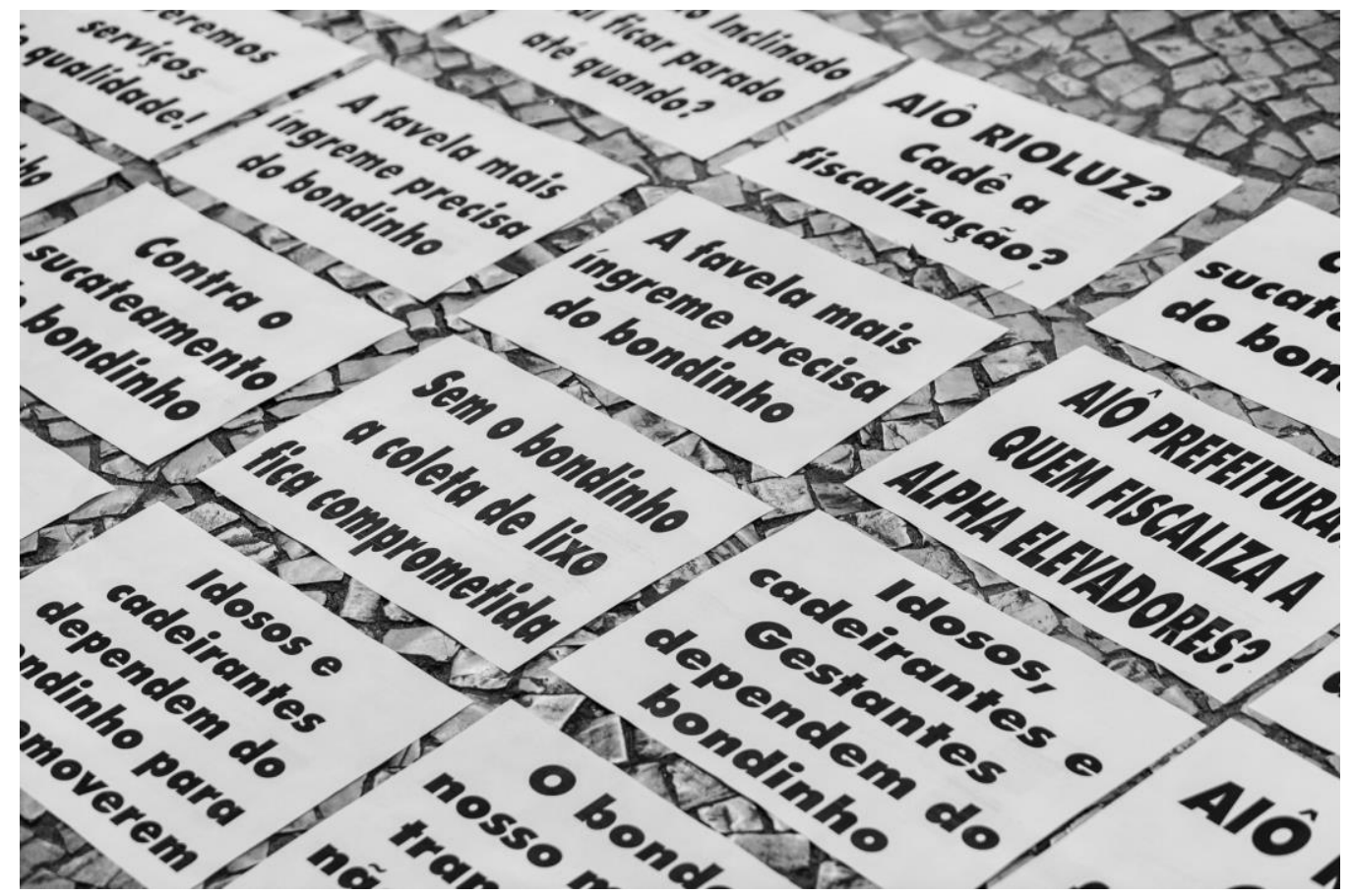

Figura 3: Cartazes elaborados com denúncias sobre serviços públicos na favela. Fonte: Facebook Página "Favela Santa Marta". ${ }^{19}$

Comentando sobre serviços que são interrompidos durante ou após sua conclusão, duas importantes lideranças se referiram ao termo "incompletude", como algo que ocorre freqüentemente sobre projetos nas favelas. De acordo com eles, independente de sua origem, este termo faz sentido porque as intervenções historicamente têm suspensão prematura, ou têm sua conclusão decretada em es tágios iniciais ou preliminares. De acordo com estes moradores, após toda uma negociação e criação de expectativa com moradores, "nada acontece e a vida continua sendo muito difícil para todos". Como apresentado na introdução deste artigo, a temporalidade da suspensão não está entre o passado e o futuro, entre o começo e o fim, mas constitui sua própria condição de ser. Em um sentido político, é significativo refletir sobre o recorte social de classe e identidade das pessoas que vivem em favelas, e de que forma is to está relacionado com o contraste social que pode serpercebido sobre a comparação "favela" e "asfalto". Anand (2017a) argumenta que a "distribuição desigual de infraestrutura está ancorada na desigualdade estrutural da vida urbana", produzida 
Dossiê | Incerteza e suspensão: notas sobre a vida material e política da infraestrutura no cotidiano da favela Santa Marta/RJ (MANO, Apoena)

através de atividades diárias na cidade. É problemático perceber como populações em favelas são historicamente afetadas por políticas públicas ineficazes e, neste caso, convivem com incertezas sobre o investimento, conclusão, funcionamento e manutenção de serviços essenciais.

\section{Considerações Finais}

Baseado em três eixos de análise questionando como o "Estado se faz ausente" na vida de moradores da favela Santa Marta, o artigo proposto mostra como a construção destes "territórios de vulnerabilidades" constitui parte da subjetividade destes moradores através de relatos de dor, precariedades, humilhações, desesperança e incertezas. Com base nas reflexões apresentadas, a interpretação de questões locais relacionadas à infraestrutura pode ajudar a compreender os jogos de poder que estão em curso no processo de formação das cidades. Neste caso, concluo que formas de governo sobre populações da favela podem ser justificadas por interesses relativos a outros grupos sociais. A precarização da infraestrutura, como distribuição de água e eletricidade, pode ser interpretada como a forma que o Estado entra na casa das pessoas e se faz presente em sua vida privada (ANAND, 2017a). Ainda que periodicamente sejam produzidas expectativas sobre a "integração das favelas à parte formal da cidade", moradores locais explicitam percepções pessimistas sobre estas formas de integração:

"Em todas as favelas, o mesmo problema. Isso revela como o poder público olha e se relaciona com a favela. Há um certo ensaio de que aquilo será tomado como parte efetiva da cidade. É um ciclo. A prefeitura atual não tem nenhum projeto para a urbanização das favelas. Veremos mais um ciclo de 4 anos sem projetos para as favelas" (Relato de morador - Junho/18)

A instalação das Unidades de Polícia Pacificadora estabeleceu uma gramática de promessas e expectativas sobre as favelas. Contudo, pode-se concluir que passados dois anos após os Jogos Olímpicos, a sensação que permeia o cotidiano da favela é marcada por suspensão e incertezas - ou o encerramento de outro ciclo. Populações de favela são percebidas pelo Estado e pela sociedade primeiramente a partir de uma narrativa relacionada à violência e criminalização dos territórios onde vivem (BURGOS, 1998; 
Dossiê | Incerteza e suspensão: notas sobre a vida material e política da infraestrutura no cotidiano da favela Santa Marta/RJ (MANO, Apoena)

VALLADARES, 2005), como no caso das UPPs, onde qualquer política é anteriormente relacionada a políticas de segurança pública. Desta forma, sobre o recorte dado à infraestrutura como chave interpretativa de relações ao seu entorno, no contexto da favela Santa Marta, pode-se concluir que a percepção relacionada às políticas de Estado se constitui a partir da criação de narrativas e efeitos caracterizados pela seletividade e exceção, que ocasionalmente é instrumentalizada por sentidos e interesses externos. Como demonstrando, parte do cotidiano na favela Santa Marta é determinado pela infraestrutura em experiências que constituem a percepção de maquiagem, esculachos e incompletude.

Analisar a vida material e política da infraestrutura também fornece pistas sobre diferentes dimensões da violência urbana que se desdobra no território da favela. Seja no caso de policiais que retiram moradores que buscavam abrigo na obra interrompida e destroem as condições precarizadas de moradias; ou nas práticas de policiais que tentam impedir a locomoção de funcionários de uma prestadora de serviços estatal que tentavam realizar reparos na distribuição de eletricidade na favela. Trata-se de evidentes práticas de ilegalismo, onde a figura do Estado surge com a capacidade de "riscar os limites de tolerância, dar terrenos para alguns, fazer pressão sobre outros, excluir uma parte, tornar útil outras, tirar proveitos daqueles" (FOUCAULT, 1983; TELLES, 2010)20. A respeito de formas de "violência infraestrutural", Ferguson (2012) estabelece uma comparação elucidativa: em casos de execução policial, habitualmente a responsabilização pelo acontecimento é direcionada ao agente que efetuou o disparo e, consequentemente, ao Estado. Entretanto, a violência que se constrói nas desigualdades que dominam as sociedades contemporâneas é muitas vezes naturalizada, invisibilizada ou enquadrada a parecer inevitável "pelas paredes, canos, fios e estradas que nos mostraram o sofrimento que resulta pela desconexão, ou total exclusão de redes de infra-estrutura". Se a mobilização de práticas e discursos relacionados à "guerra" no Rio de Janeiro engendra dispositivos que desvalorizam as vidas e justificam um cotidiano de conflitos armados e formas de violência em territórios

\footnotetext{
20 llegalismos não são imperfeições ou lacunas na aplicação das leis, mas compõem os jogos de poder e se distribuem conforme se diferenciam "os espaços protegidos e aproveitáveis em que a lei pode ser violada, outros em que pode ser ignorada, outros, enfim, em que as infrações são sancionadas" (FOUCAULT, 1983). Uma "gestão diferencial do ilegalismos" secompõe a partir de uma análise crítica ao que ocorre nas chamadas dobras do legal-ilegal (TELLES, 2010).
} 
Dossiê | Incerteza e suspensão: notas sobre a vida material e política da infraestrutura no cotidiano da favela Santa Marta/RJ (MANO, Apoena)

específicos (LEITE, 2017), a discussão proposta neste trabalho permite uma consideração complementar: a análise crítica da organização material e das agências constitutivas de determinados territórios corrobora o argumento de que "a disposição e práticas relativas à infraestrutura não apenas refletem, mas reforçam as ordens sociais vigentes" (FERGUSON, 2012). Em outras palavras, tanto a precarização quanto a interferência no acesso a direitos básicos resultam na falência de sistemas de sobrevivência das populações locais - uma vitória sobre um suposto inimigo em uma "guerra infraestrutural" (MBEMBE, 2016).

Apoiado sobre a noção de biopolítica cunhada por Foucault, que teoriza sobre a técnica governamental voltada a populações de "fazer viver e deixar morrer" para o estabelecimento de vidas úteis, produtoras de valor e reprodutoras do capital (FOUCAULT, 2010), o filósofo camaronês Achille Mbembe mobiliza este conceito para ir além demonstrando que ao invés de "dar a vida", o Estado pode "promover a morte" ao distribuir de forma não-igualitária os direitos de sobrevivência (MBEMBE, 2016). Assim, a necropolítica se aplica a vidas supostamente dispensáveis para a reprodução do capital, intermediada pela técnica do "fazer morrer e deixar viver" - uma marginalização sociopolítica geralmente direcionada a corpos pretos, pobres e periféricos, ou a territórios demarcados por essa representação social em um devir negro na sociedade contemporânea. Favelas e periferias pobres das grandes cidades são historicamente precarizados e tornados alvos de distintos "mecanismos técnicos para conduzir pessoas à morte". Este trabalho discute sobre formas heterogêneas da necropolítica evidenciadas em múltiplos sentidos, estratégias, práticas e dispositivos que compõem formas de exposição à vulnerabilidade, ao sofrimento e, no limite, à morte (MBEMBE, 2016). A violência difusa revela linhas de continuidade destas técnicas de necropolítica, onde simultaneamente a infraestrutura não é apenas uma incorporação material da violência, mas também um meio instrumental que permite pensar sentidos aproximados onde "dar a vida e dar a morte" ocorrem simultaneamente por interesses contrapostos, resultando em vidas e populações racializadas e hierarquizadas (FERGUSON, 2012; RODGERS; O'NEILL, 2012; BENTO, 2018). 
Dossiê | Incerteza e suspensão: notas sobre a vida material e política da infraestrutura no cotidiano da favela Santa Marta/RJ (MANO, Apoena)

\section{Bibliografia}

ANAND, N. Hydraulic city: Water and the infrastructures of citizenship in Mumbai. [s.I.] Duke University Press, 2017a.

ANAND, N. The banality of infrastructure. Items Insights from the Social Sciences, Series Just Environments, 2017b.

ANAND, N.; GUPTA, A.; APPEL, H. The promise of infrastructure. [s.I.] Duke University Press, 2018.

APPEL, H.; ANAND, N.; GUPTA, A. The infrastructure toolbox. Cultural Anthropology Online] http://www. culanth. org/fieldsights/725-the-infrastructuretoolbox (Accessed 22 October 2015), 2015.

BENTO, B. Necrobiopoder: Quem pode habitar o Estado-nação? cadernos pagu, $n$. 53, 2018.

BIRMAN, P.; FERNANDES, A.; PIEROBON, C. Um emaranhado de casos: tráfico de drogas, estado e precariedade em moradias populares. Mana, v. 20, n. 3, p. 431-460, 2014.

BURGOS, M. B. Dos parques proletários ao Favela-Bairro: as políticas públicas nas favelas do Rio de Janeiro. Um século de favela, v. 5, p. 25-60, 1998.

BURGOS, M. B. et al. O efeito UPP na percepção dos moradores das favelas. Desigualdade \& Diversidade, v. 11, p. 49, 2011.

CAVALCANTI, M. Ã€ espera, em ruínas: Urbanismo, estética e política no Rio de Janeiro da 'PACificação'”'. Dilemas-Revista de Estudos de Conflito e Controle Social, v. 6, n. 2, p. 191-228, 2013.

CUNHA, N. V. DA; MELLO, M. A. DA S. Novos conflitos na cidade: a UPP e o processo de urbanização na favela. 2011.

DAS, V. Fronteiras, violência e o trabalho do tempo: alguns temas wittgensteinianos. Revista brasileira de ciências sociais, v. 14, n. 40, p. 31-42, 1999.

DAS, V. The signature of the state: the paradox of illegibility. Anthropology in the Margins of the State, p. 225-252, 2004.

DAS, V.; POOLE, D. Anthropology in the Margins of the State. [s.I.] Oxford: James Currey, 2004. 
Dossiê | Incerteza e suspensão: notas sobre a vida material e política da infraestrutura no cotidiano da favela Santa Marta/RJ (MANO, Apoena)

FERGUSON, J. Structures of responsibility. Ethnography, v. 13, n. 4, p. 558-562, 2012.

FOUCAULT, M. Vigiar e punir: História da violência nas prisões. [1975] 2ª Edição ed. [s.l.] Petrópolis: Vozes, 1983.

FOUCAULT, M. Microfísica do poder. [1979] 28ª reimpressão ed. [s.I.] São Paulo: Graal, 2010.

FRANGELLA, S.; RUI, T. CORPOS PRECÁRIOS: apontamentos para a relação entre corpo e cidade. REVISTA DE CIÊNCIAS SOCIAIS-POLÍTICA \& TRABALHO, v. 1, n. 47, p. 23-38, 2018.

GUTTERRES, A. DOS S. O rumor e o terror na construção de territórios de vulnerabilidade na zona portuária do Rio de Janeiro. Mana, v. 22, n. 1, p. 179-209, 2016.

LEITE, M. P. State, market and administration of territories in the city of Rio de Janeiro. Vibrant: Virtual Brazilian Anthropology, v. 14, n. 3, 2017.

MAGALHÃES, A. O "legado" dos megaeventos esportivos: a reatualização da remoção de favelas no Rio de Janeiro. Horizontes Antropológicos, v. 19, n. 40, p. 89118, 2013.

MBEMBE, A. Necropolítica. Revista do PPGAV/EBA/UFRJ, n. n. 32, 2016.

MENEZES, P. Será que estaremos aqui quando as Olimpíadas chegarem? Novas oportunidades e preocupações pós-UPP na "favela modelo". Trama: indústria criativa em revista ISSN 2447-7516, v. 1, n. 1, 2015.

PIEROBON, C. Tempos que duram e lutas que não acabam: o cotidiano de Leonor e sua ética de combate. PhD Thesis - [s.I.] Tese de Doutorado. PPCIS/Universidade do Estado do Rio de Janeiro, 2018.

RODGERS, D.; O'NEILL, B. Infrastructural violence: Introduction to the special issue. Ethnography, v. 13, n. 4, p. 401-412, 2012.

ROY, A. Urban informality: toward an epistemology of planning. Journal of the american planning association, v. 71, n. 2, p. 147-158, 2005.

TELLES, V. Cidade: produção de espaços, formas de controle e conflitos. Revista de Ciências sociais, v. 46, n. 1, p. 15-41, 2015.

TELLES, V. DA S. A cidade nas fronteiras do legal e ilegal. [s.I.] Argumentum, 2010.

VALLADARES, L. A invenção da favela: do mito de origem a favela. com. [s.I.] editora FGV, 2005. 
Dossiê | Incerteza e suspensão: notas sobre a vida material e política da infraestrutura no cotidiano da favela Santa Marta/RJ (MANO, Apoena)

\section{Reportagens}

(ELPAÍS, 2018) - UPPs, mais uma história de esperança e fracasso na segurança pública do Rio. Disponível em: <https://brasil.elpais.com/brasil/2018/03/11/politica/1520769227 645322.html> Acesso em: 16/08/2018

(EXTRA, 2018) - Teleféricos do Alemão e da Providência viram sucata. Disponível em: $\quad$ https://extra.globo.com/noticias/rio/telefericos-do-alemao-da-providenciaviram-sucata-22553797.html> Acesso em: 02/02/2019

(JORNAL DO BRASIL, 2018) - Caos sobe o morro: Crise paralisa obras na Santa Marta e muro para conter expansão aumenta área Disponível em: <https://www.jb.com.br/index.php?id=/acervo/materia.php\&cd_matia=902953\&dina mico=1\&preview=1/> Acesso em: 16/08/2018

(O GLOBO, 2017) - Plano inclinado do morro Dona Marta está parado por falta de verba Disponível em: <https://oglobo.globo.com/rio/plano-inclinado-do-morro-donamarta-esta-parado-por-falta-de-verba-22159181> Acesso em: 02/02/2019

(O GLOBO, 2012) - Morro Dona Marta: primeira favela com UPP sofre com esgoto Disponível em: <https://oglobo.globo.com/rio/morro-dona-marta-primeira-favelacom-upp-sofre-com-esgoto-6855247> Acesso em: 16/08/2018

(RJTV1, 2018) - Comunidade RJ foi até o Santa Marta e mostrou prédio abandonados e moradores sem casas Disponível em: <https://globoplay.globo.com/v/986287/> Acesso em: 16/08/2018 